\title{
PROGNOSTIC IMPORTANCE OF TISSUE DOPPLER IMAGING OF SYSTOLIC AND DIASTOLIC FUNCTIONS IN DOGS WITH SEVERE SEPSIS AND SEPTIC SHOCK
}

\author{
Mehmet Ege INCE ${ }^{1}$, Kursad TURGUT $^{1 *}$, Aybars AKAR $^{2}$, Amir NASERI $^{3}$, Ismail SEN ${ }^{4}$, \\ Havva SÜLEYMANOGLU ${ }^{1}$, Merve ERTAN ${ }^{1}$ and Vedat SAGMANLIGIL ${ }^{5}$ \\ ${ }^{1}$ Department of Internal Medicine, Faculty of Veterinary Medicine, Near East University, \\ 99138 Nicosia, North Cyprus, Turkey; ${ }^{2}$ Department of Internal Medicine, Faculty \\ of Veterinary Medicine, Mehmet Akif Ersoy University, Turkey; ${ }^{3}$ Department \\ of Internal Medicine, Faculty of Veterinary Medicine, Selcuk University, Konya, Turkey; \\ ${ }^{4}$ Department of Internal Medicine, Faculty of Veterinary Medicine, Kyrgyz Turkish \\ Manas University, Bishkek, Kyrgyzstan; ${ }^{5}$ Department of Physiology, Faculty \\ of Veterinary Medicine, Near East University, Nicosia, North Cyprus, Turkey
}

(Received 11 March 2019; accepted 29 August 2019)

The goal of this study was to determine the distribution of left ventricular (LV) systolic and diastolic dysfunctions and their prognostic value in canine parvovirus-infected dogs suffering from severe sepsis and septic shock (SS/SS). Twenty dogs with SS/SS (experimental group) and 18 healthy dogs (control group) were used in the study. Systolic and diastolic dysfunction was present in three $(15 \%)$ and $14(70 \%)$ diseased dogs, respectively, with both types of dysfunction present in two $(10 \%)$ of the patients. These dogs were split into two groups: survivors $(\mathrm{Sv}, \mathrm{n}=14)$ and non-survivors (non-Sv, $\mathrm{n}=6)$. The pulsed wave tissue Doppler (PW-TDI) septal mitral annulus systolic velocity (LVS'), an index of systolic dysfunction, had a high sensitivity and specificity to differentiate $\mathrm{Sv}$ and non-Sv animals, with values of $83.3 \%$ (95\% CI: 41.6-98.4) and 83.3\% (95\% CI: 59.8-94.8), respectively, at an optimum cut-off point of $\geq 9.90$. The PW-TDI septal early mitral annulus early-diastolic peak velocity (E'), an index of diastolic dysfunction, had the best sensitivity and specificity to differentiate $\mathrm{Sv}$ and non-Sv dogs, with values of 100\% (95\% CI: 55.2-100) and 100\% (95\% CI: 78.9-100), respectively, at an optimum cut-off point of $\leq 6.50$. Therefore, diastolic dysfunction determined by $\mathrm{E}^{\prime}$ is a good independent outcome predictor.

Key words: Sepsis, septic shock, dogs, parvovirus, myocardial dysfunction, echocardiography

Canine parvovirus infection (CPVI) is a disease characterised by severe enteritis, profuse diarrhoea, and myocarditis due to not only canine parvovirus (CPV) but also to sepsis-induced myocardial depression (SiMD) in dogs (Otto, 2007).

*Corresponding author; E-mail: kursad.turgut@neu.edu.tr; Phone: 0090 (535) 887-4202 
Transthoracic echocardiography (TTE) is a technique for guiding haemodynamic management of cardiac function in human patients in the intensive care unit (ICU) (Rolando et al., 2015; Naseri et al., 2019). Tissue Doppler Imaging (TDI) provides a quantitative assessment of myocardial motion for the evaluation of systolic and diastolic function. TDI is less load dependent than conventional echocardiography techniques, and provides an assessment of global systolic and diastolic left ventricular (LV) function (Abdel-Hady et al., 2012; Souza Dantas and Costa, 2015).

SiMD is a reversible dysfunction causing both systolic and diastolic dysfunction (Antonucci et al., 2014). Its incidence changes from 20 to $60 \%$ in the first three days after the onset of septic shock and generally returns to normal within 7-10 days (Vieillard-Baron et al., 2008; Vieillard-Baron, 2011). Mortality rate in patients with SiMD (70\%) has been found to be significantly higher than in septic patients without SiMD (20\%) (Parrillo et al., 1990; Bulmer, 2011). In humans, most studies have been performed on LV systolic dysfunction in sepsis (Krishnagopalan et al., 2002; Vieillard-Baron et al., 2008; Souza Dantas and Costa, 2015); however, other forms of SiMD such as LV diastolic dysfunction and right ventricular dysfunction have been poorly evaluated (Bouhemad et al., 2008; Sturgess et al., 2010; Mahjoub et al., 2012; De Geer et al., 2015). All types of SiMD which may be reversible with resolution of the critical illness can be present in isolation or in combination (Bouhemad et al., 2008). The studies on SiMD show that diastolic dysfunction is associated with a higher mortality rate than systolic dysfunction (Landesberg et al., 2012; Rolando et al., 2015).

Although canine models have been used to evaluate the pathogenesis of cardiovascular dysfunction in sepsis, studies on clinical cases concerning its prevalence and prognosis is limited (Bulmer, 2011). Nelson and Thompson (2006) reported that 16 dogs with severe systemic illness had LV dysfunction, twelve of which died or were euthanised within 15 days of hospitalisation. The average survival time of these dogs was 3.6 days. Kocaturk et al. (2012) stated that 43 dogs with CPVI had an elevated myocardial performance index (Tei) and increased serum cardiac troponin-I (cTnI). They found that these two parameters were also associated with a poor prognosis. The parameters used for evaluating systolic and diastolic dysfunction are essential for the monitoring of dogs with sepsis. Parameters such as ejection fraction (EF), LVS', E', E/E', end-diastolic volume index (EDVI) and end-systolic volume index (ESVI) are often used to monitor septic human patients because of their good prognostic value. However, the importance of these parameters, their association to one another, prognostic cut-off values for the best differentiation between survivors (Sv) and non-survivors (nonSv) and their applicability are unknown in dogs with severe sepsis and septic shock (SS/SS).

Thus, the first goal of this study was to determine the distribution of LV systolic and diastolic dysfunctions and their prognostic value in canine parvovi- 
rus-infected dogs with SS/SS at admission to the ICU. The second goal was to determine prognostic cut-off values of the systolic and diastolic indices for the best differentiation between $\mathrm{Sv}$ and non-Sv animals.

\section{Materials and methods}

This study received ethics committee approval from the Faculty of Veterinary Medicine, University of Selcuk (permit number: 2012/053). Twenty dogs suffering from CPVI with SS/SS (experimental group) and 18 healthy dogs (control group), incorporating both sexes and different breed types, $\leq 6$ months of age, were used during the years 2014-2017.

The control dogs, which were brought to the clinic for vaccination, were deemed healthy according to the clinical and laboratory examinations and negative commercial SNAP CPV antigen test (IDEXX, SNAPshot Dx). The 3-min ECG recordings and echocardiography examination results of the control dogs were also normal.

The experimental dogs had clinical signs (vomiting and/or bloody diarrhoea) and laboratory findings (granulocytopenia and/or lymphopenia) compatible with CPVI. All of them had a positive result by the SNAP CPV antigen test (IDEXX, SNAPshot Dx), and none of them had been vaccinated with commercial parvovirus vaccine. Inclusion criteria in the experimental group were the recognition of systemic inflammatory response syndrome and SS/SS. The dogs were excluded from the study if they had congenital heart diseases, crude echocardiographic images and measurements, and had received any other therapy.

The presence of systemic inflammatory response syndrome, SS/SS in the experimental group of dogs was determined according to Silverstein and Hoper (2015). Sepsis associated with organ dysfunction, hypoperfusion, or hypotension was defined as severe sepsis. When severe sepsis did not respond to one bolus of IV fluid administration, it was regarded as septic shock. Hypotension was defined as systolic blood pressure (SBP) $<90 \mathrm{mmHg}$ and mean blood pressure $(\mathrm{MBP})<70 \mathrm{~mm} \mathrm{Hg}$. A lactate level higher than $2.2 \mathrm{mmol} / \mathrm{L}$ was considered indicative of hypoperfusion.

Dogs of the experimental group were monitored (SBP and MBP, ECG recordings) in the ICU (Compact 7, Medical Econet, Germany), and treated as described by McMichael (2014). In cases with diastolic dysfunction, a colloid solution (hydroxyethyl starch $6 \%, 10 \mathrm{ml} / \mathrm{kg} / \mathrm{h}, \mathrm{IV}$ ) was given to prevent the development positive fluid balance due to the use of large amounts of crystalloid solution.

All the clinical, laboratory and cardiologic examinations of the experimental group of dogs were performed within $3 \mathrm{~h}$ of admission and thereafter at 6 and $24 \mathrm{~h}$ of the treatment and on the day of discharge. Blood samples were obtained for measurements of the concentration of cardiac troponin I (cTnI) by commercial ELISA (Mybiosource, USA). 
Echocardiographic evaluation and definitions of left ventricular systolic and diastolic dysfunction

TTE was applied in the ICU with an echocardiograph (SUIU, CZXL43C). Comprehensive 2-dimensional, M-mode and Doppler echocardiographic examinations were performed on all experimental dogs from the right parasternal views (long- and short-axis) and apical views (4-chamber).

Left ventricular end-diastolic volume (EDV), end-systolic volume (ESV) and ejection fraction (EF) were measured using the Teichholz method using the software program of the echocardiogram as recommended by Turgut (2017). All measurements were made from three cardiac cycles and the mean values calculated. LV systolic dysfunction was described as mild (EF, 41-50\%) and moderate (EF, 31-40\%) (Turgut, 2017). The EDV, ESV and cardiac output values were indexed according to body surface area, to obtain the EDV index (EDVI), ESV index (ESVI) and the cardiac index (CI). Mitral inflow PW-Doppler measurement of peak $\mathrm{E}$ and $\mathrm{A}$ waves, $\mathrm{E} / \mathrm{A}$ ratio, and peak $\mathrm{E}$ deceleration time were determined. PW-TDI septal mitral annulus systolic (LVS') and early diastolic (E') velocities were obtained. The E/E' ratio was then calculated (Nagueh et al., 2009). Diastolic function was described based on the 2009 guidelines of the American Society of Echocardiography (ASE) (Nagueh et al., 2009) and classified as follows: if $\mathrm{E}^{\prime} \geq 8 \mathrm{~cm} / \mathrm{s}$ : normal; if $\mathrm{E}^{\prime}<8 \mathrm{~cm} / \mathrm{s}$ and $\mathrm{E} / \mathrm{A}<0.8$ : impaired relaxation; if $\mathrm{E}^{\prime}<8 \mathrm{~cm} / \mathrm{s}, \mathrm{E} / \mathrm{A} 0.8-1.5$ and $\mathrm{E} / \mathrm{E}^{\prime}$ 9-12: pseudonormal; if $\mathrm{E}^{\prime}<8 \mathrm{~cm} / \mathrm{s}$, $\mathrm{E} / \mathrm{A}>2, \mathrm{DT}<160 \mathrm{~ms}$ and $\mathrm{E} / \mathrm{E}^{\prime} \geq 13$ : restrictive.

\section{Patient follow-up}

The experimental group of dogs was followed for 28-day mortality. A total of 65 echocardiograms were performed and the dogs were split into two groups ( $\mathrm{Sv}$ and non-Sv) according to their treatment response.

\section{Statistical analysis}

All data were normalised by logarithmic transformation before analysis. Parametric data are reported as mean \pm SD. These data were compared using an unpaired $t$-test. Nonparametric data are reported as median and range. Multivariate regression analysis of ICU mortality was made to determine independent predictors of mortality. The prognostic values of LVS', E', EF and E/A for 28day mortality were evaluated using receiver operating characteristic (ROC) curve analysis in order to determine the prognostic cut-off value for the best differentiation between Sv and non-Sv (SPSS Inc). Values at the level P $<0.05$ were considered as significant. 


\section{Results}

Age, body weight and sex differences between $\mathrm{Sv}$ and non-Sv groups were not significant. The clinical and laboratory results including cTnI also did not show any significant difference between the Sv and non-Sv groups (Tables 1 and 2). Hypotension (SBP $<90 \mathrm{mmHg}$ and/or $\mathrm{MBP}<65 \mathrm{mmHg}$ ) was evident in 8 of 20 CPV-infected dogs with severe sepsis, two of which still had low BP at the 6th hour of treatment (septic shock).

In the experimental group, 15 dogs (75\%) had at least one type of myocardial dysfunction. Systolic $(\mathrm{EF} \leq 50 \%)$ and diastolic dysfunction $\left(\mathrm{E}^{\prime}<8 \mathrm{~cm} / \mathrm{s}\right)$ was present in three (15\%) and $14(70 \%)$ patients, respectively, and both types of dysfunction were present in two $(10 \%)$ patients. One dog with severe sepsis had neither systolic nor diastolic dysfunction. Within the LV diastolic dysfunction group, 11 patients $(55 \%)$ had impaired relaxation and three $(15 \%)$ had pseudonormal dysfunction. Within the LV systolic dysfunction group, two patients $(10 \%)$ had mild dysfunction and one $(5 \%)$ had moderate dysfunction.

Fourteen dogs recovered and were discharged from the ICU (Sv). Six patients died (four during the first $6 \mathrm{~h}$ and two between the 2nd and 4th day of the study), resulting in an overall mortality rate of $30 \%$ (non-Sv). The average length of survival was $1.3 \pm 1.4$ days for the non-Sv dogs $(n=6 ; 30 \%)$, but the rest of the dogs $(n=14 ; 70 \%)$ survived. None of the dogs with systolic dysfunction died, while six dogs with diastolic dysfunction did not survive. The patients with an E' $<8 \mathrm{~cm} / \mathrm{s}$ had the worse survival outcome. Patients with systolic dysfunction (three patients) and the survived patients with LV diastolic dysfunction (eight patients) and two dogs with both systolic and diastolic types dysfunction on the initial echocardiogram had normal systolic and diastolic function on their final echocardiogram.

Multivariate regression analysis of ICU mortality showed that LVS', E', $\mathrm{EF}$ and $\mathrm{E} / \mathrm{A}$ were independent predictors of mortality (Table 2). The cardiological findings on admission for the Sv and non-Sv are shown in Table 2. The EF for non-Sv dogs $(74 \pm 10.48 \%)$ was significantly higher than that of Sv $(62.22 \pm$ $13.16 \%$; $\mathrm{P}<0.05$ ) (Table 2). Higher LVS' was determined in non-Sv dogs, compared to $\mathrm{Sv}(\mathrm{P}<0.05)$ and control dogs $(\mathrm{P}<0.05)$. In non-Sv dogs, the average $\mathrm{E} / \mathrm{A}$ ratio and $\mathrm{E}$ ' were significantly lower $(\mathrm{P}<0.05)$ than those of the control and Sv dogs (Table 2). The LVS', an index of systolic dysfunction, had high sensitivity and specificity to differentiate Sv and non-Sv, with values of $83.3 \%$ (95\% CI: 41.6-98.4) and $83.3 \%$ (95\% CI: 59.8-94.8), respectively, at an optimum cut-off point of $\geq 9.90$. The E', an index of diastolic dysfunction, had the best sensitivity and specificity to differentiate $\mathrm{Sv}$ and non-Sv, with values of $100 \%(95 \% \mathrm{CI}$ : 55.2-100) and $100 \%$ (95\% CI: 78.9-100), respectively, at an optimum cut-off point of $\leq 6.50$ (Table 3$)$. 
The sensitivity and specificity of EF and E/A were not high enough to differentiate Sv and non-Sv (Table 3).

\section{Table 1}

Clinical and laboratory parameters (mean \pm standard deviation and mid) in control dogs $(\mathrm{n}=18)$ and survivor $(\mathrm{n}=16)$ and non-survivors $(\mathrm{n}=6)$ dogs with parvoviral enteritis

\begin{tabular}{|c|c|c|c|}
\hline Parameters & Control & Survivor & Non-survivor \\
\hline Body temperature $\left({ }^{\circ} \mathrm{C}\right)$ & $41.37 \pm 11.62$ & $38.9 \pm 0.87$ & $38.53 \pm 1.4$ \\
\hline Respiration rate (bpm) & $27.77 \pm 3.05$ & $47.92 \pm 16.36^{\mathrm{a}}$ & $41.16 \pm 16.53$ \\
\hline Dehydration rate & 1 & $2.07 \pm 0.91^{\mathrm{a}}$ & $2 \pm 0.63^{\mathrm{a}}$ \\
\hline Capillary refill time (sec) & 1 & $2.57 \pm 0.51^{\mathrm{a}}$ & $2.5 \pm 0.54^{\mathrm{a}}$ \\
\hline Mucous membranes & 2 & $2.42 \pm 0.85$ & $1.83 \pm 0.98^{\mathrm{a}}$ \\
\hline Femoral pulse & 2 & $1.5 \pm 0.51^{\mathrm{a}}$ & $1.16 \pm 0.40^{\mathrm{a}}$ \\
\hline Mental state & 4 & $2 \pm 0.55^{\mathrm{a}}$ & $2^{\mathrm{a}}$ \\
\hline Diarrhoea & 1 & $2.85 \pm 0.36^{\mathrm{a}}$ & $3^{\mathrm{a}}$ \\
\hline WBC $\left(10^{9} / \mathrm{L}\right)$ & 14.57 & $8.68 \pm 7.73^{\mathrm{a}}$ & $7.64 \pm 8.13$ \\
\hline Lymphocytes $\left(10^{9} / \mathrm{L}\right)$ & 3.84 & $5.17 \pm 4.24$ & $5.23 \pm 4.9$ \\
\hline Monocytes $\left(10^{9} / \mathrm{L}\right)$ & 0.8 & $0.55 \pm 0.8$ & $0.95 \pm 2.12$ \\
\hline Granulocytes $\left(10^{9} / \mathrm{L}\right)$ & $9.1 \pm 5.57$ & $2.99 \pm 3.02^{\mathrm{a}}$ & $1.45 \pm 2.04^{\mathrm{a}}$ \\
\hline $\operatorname{RBC}\left(10^{12} / \mathrm{L}\right)$ & $5.83 \pm 1.02$ & $7.65 \pm 1.26^{\mathrm{a}}$ & $7.13 \pm 1.18$ \\
\hline $\mathrm{MCV}(\mathrm{fL})$ & $57.43 \pm 6.26$ & $61.14 \pm 3.75$ & $61.25 \pm 4.30$ \\
\hline Het $(\%)$ & $33.35 \pm 7.91$ & $46.74 \pm 8.07^{\mathrm{a}}$ & $43.56 \pm 8.85^{\mathrm{a}}$ \\
\hline MCHC (g/dL) & $35.70 \pm 17.39$ & $30.92 \pm 2.61$ & $28.06 \pm 4.26$ \\
\hline $\mathrm{Hb}(\mathrm{g} / \mathrm{dL})$ & $11.67 \pm 1.18$ & $14.76 \pm 2.51^{\mathrm{a}}$ & $12.45 \pm 3.85$ \\
\hline $\mathrm{pH}$ & $7.37 \pm 0.03$ & $7.31 \pm 0.1$ & $7.36 \pm 0.06$ \\
\hline $\mathrm{pCO}_{2}(\mathrm{mmHg})$ & $36.82 \pm 3.40$ & $40.77 \pm 8.34$ & $42.13 \pm 9.22$ \\
\hline $\mathrm{pO}_{2}(\mathrm{mmHg})$ & $37.19 \pm 6.24$ & $29.14 \pm 7.65^{\mathrm{a}}$ & $29.83 \pm 6.67$ \\
\hline $\mathrm{Na}(\mathrm{mmol} / \mathrm{L})$ & $146.72 \pm 6.41$ & $141.92 \pm 4.32^{\mathrm{a}}$ & $141.33 \pm 1.36$ \\
\hline $\mathrm{K}(\mathrm{mmol} / \mathrm{L})$ & $3.65 \pm 0.51$ & $3.61 \pm 0.37$ & $3.4 \pm 0.67$ \\
\hline Lactate $(\mathrm{mmol} / \mathrm{L})$ & 1.3 & $3.19 \pm 2.23^{\mathrm{a}}$ & $1.91 \pm 1.24$ \\
\hline $\mathrm{HCO}_{3}(\mathrm{mmol} / \mathrm{L})$ & $22.76 \pm 2.13$ & $20.7 \pm 3.61$ & $23.91 \pm 7.78$ \\
\hline $\mathrm{BE}(\mathrm{mmol} / \mathrm{L})$ & $-1.19 \pm 2.72$ & $-5.46 \pm 4.79^{\mathrm{a}}$ & $-1.23 \pm 8.26$ \\
\hline $\mathrm{SO}_{2}(\%)$ & $87.33 \pm 4.31$ & $47.62 \pm 19.88^{\mathrm{a}}$ & $51.38 \pm 18.33^{\mathrm{a}}$ \\
\hline Glucose (mg/dL) & $93.38 \pm 12.94$ & $92.42 \pm 30.4$ & $112.66 \pm 33.64$ \\
\hline BUN (mg/dL) & 11 & $19.57 \pm 15.57$ & $14.83 \pm 10.53$ \\
\hline Creatinine (mg/dL) & 0.5 & $0.58 \pm 0.74$ & $0.8 \pm 0.54$ \\
\hline $\operatorname{ALT}(\mathrm{U} / \mathrm{L})$ & 27 & $39.21 \pm 30.86$ & $101 \pm 80.27^{\mathrm{a}}$ \\
\hline ALP (U/L) & $249.97 \pm 152.1$ & $305.71 \pm 142.83$ & $284 \pm 83.84$ \\
\hline Albumin (g/dL) & $2.6 \pm 0.46$ & $2.67 \pm 0.34$ & $2.30 \pm 0.23$ \\
\hline Protein $(\mathrm{g} / \mathrm{dL})$ & $5.69 \pm 1.01$ & $5.72 \pm 0.73$ & $5.05 \pm 0.44$ \\
\hline
\end{tabular}

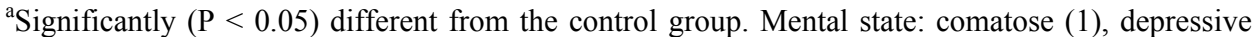
(2), alert (3), active (4); Diarrhoea: none (1), watery diarrhoea (2), haemorrhagic diarrhoea (3); Femoral pulse: normokinetic (2), hypokinetic (1); Mucous membranes: hyperaemic (1), normal (2), slightly pale (3), pale (4); Dehydration rate: $<5 \%$ (1); 6-8\% (2); $9-10 \%(3) ;>10 \%$ (4); Capillary Refill Time: $<2 \sec (1) ; 3-4 \sec (2) ; 4-5 \sec (3)$ 
Table 2

Echocardiographic parameters (mean \pm standard deviation) and cardiac troponin I (mid) in control $\operatorname{dogs}(n=18)$ and survivor $(n=14)$ and non-survivors $(n=6)$ dogs with parvoviral enteritis

\begin{tabular}{lccc}
\hline Parameters & Control & Survivor & Non-survivor \\
\hline HR (BPM) & $122.66 \pm 24.81$ & $179.92 \pm 33.08^{\mathrm{a}}$ & $195.83 \pm 36.1^{\mathrm{a}}$ \\
SBP $(\mathrm{mmHg})$ & $126.05 \pm 17.94$ & $117.5 \pm 27.68$ & $89.16 \pm 32.93^{\mathrm{a}}$ \\
MAP $(\mathrm{mmHg})$ & $93.38 \pm 17.46$ & $82.64 \pm 25.96$ & $68.16 \pm 21.09^{\mathrm{a}}$ \\
EDVI $\left(\mathrm{mL} / \mathrm{m}^{2}\right)$ & $64.49 \pm 17.19$ & $30.54 \pm 9.19^{\mathrm{a}}$ & $28.17 \pm 14.41^{\mathrm{a}}$ \\
ESVI $\left(\mathrm{mL} / \mathrm{m}^{2}\right)$ & $21.71 \pm 5.35$ & $11.47 \pm 6.73^{\mathrm{a}}$ & $13.3 \pm 10.06^{\mathrm{a}}$ \\
EF \% & $63.49 \pm 4.5$ & $62.22 \pm 13.16$ & $74 \pm 10.48^{\mathrm{b}}$ \\
CI $\left(\mathrm{mL} / \mathrm{min} / \mathrm{m}^{2}\right)$ & $5547.38 \pm 1041.94$ & $3094.08 \pm 764.26^{\mathrm{a}}$ & $2768.37 \pm 1184.8^{\mathrm{a}}$ \\
LVS' (cm/sec) & $8.49 \pm 1.3$ & $8.49 \pm 2.06$ & $11.75 \pm 2.37^{\mathrm{ab}}$ \\
EPSS (mm) & $0.30 \pm 0.08$ & $0.23 \pm 0.11$ & $0.25 \pm 0.11$ \\
E $(\mathrm{cm} / \mathrm{sec})$ & $77.76 \pm 13.28$ & $55.51 \pm 16.01^{\mathrm{a}}$ & $41.85 \pm 5.66^{\mathrm{a}}$ \\
A $(\mathrm{cm} / \mathrm{sec})$ & $53.33 \pm 8.76$ & $55.80 \pm 23.68$ & $49.85 \pm 15.72$ \\
E/A ratio & $1.46 \pm 0.17$ & $1.16 \pm 0.44^{\mathrm{a}}$ & $0.78 \pm 0.15^{\mathrm{ab}}$ \\
E deceleration time $(\mathrm{sec})$ & $0.04 \pm 0.01$ & $0.06 \pm 0.02$ & $0.05 \pm 0.01$ \\
E' (cm/sec) & $10.87 \pm 1.41$ & $7.14 \pm 1.91^{\mathrm{a}}$ & $5.55 \pm 1.26^{\mathrm{ab}}$ \\
E/E' & $7.34 \pm 0.76$ & $7.12 \pm 2.33$ & $7.01 \pm 1.55$ \\
cTnI (pg/mL) & 5.6 & $21.03 \pm 22.2$ & $22.4 \pm 16.23$ \\
\hline
\end{tabular}

$\mathrm{EF}=$ Ejection fraction; $\mathrm{E} / \mathrm{A}$ ratio $=$ Mitral ratio of peak early $(\mathrm{E})$ to late diastolic filling velocity

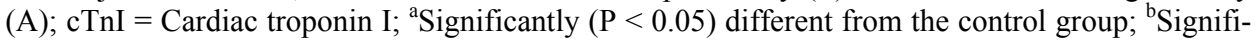
cantly $(\mathrm{P}<0.05)$ different from the survivor group

\section{Table 3}

Optimum cut-off values of PW-TDI septal mitral annulus systolic (LVS'), early diastolic velocities (E'), EF and E/A, and respective sensitivity, specificity, area under the curve (AUC), standard deviation (SD), and likelihood ratio of mortality prediction in CPV-infected dogs

\begin{tabular}{|c|c|c|c|c|c|c|c|c|c|}
\hline Item & Cut-off & AUC & SE & $\begin{array}{l}95 \% \mathrm{CI} \\
\text { for AUC }\end{array}$ & $\begin{array}{l}\text { Sensitivity } \\
(95 \% \mathrm{CI})\end{array}$ & $\begin{array}{c}\text { Specificity } \\
(95 \% \mathrm{CI})\end{array}$ & PPV & NPV & Accuracy \\
\hline $\begin{array}{l}\text { LVS' } \\
(\mathrm{cm} / \mathrm{s})\end{array}$ & $\geq 9.90$ & 0.880 & 0.061 & $0.760-0.999$ & $\begin{array}{c}83.3 \\
(41.6-98.4) \\
(\mathbf{P}<\mathbf{0 . 0 5})\end{array}$ & $\begin{array}{c}83.3 \\
(59.8-94.8) \\
(\mathbf{P}<\mathbf{0 . 0 5})\end{array}$ & 62.5 & 93.8 & 83.3 \\
\hline $\begin{array}{l}E^{\prime} \\
(\mathrm{cm} / \mathrm{s})\end{array}$ & $\leq 6.50$ & 1.000 & 0.000 & $1.000-1.000$ & $\begin{array}{c}100 \\
(55.2-100) \\
(\mathbf{P}<\mathbf{0 . 0 0 1})\end{array}$ & $\begin{array}{c}100 \\
(78.9-100) \\
(\mathbf{P}<\mathbf{0 . 0 0 1})\end{array}$ & 100 & 100 & 100 \\
\hline $\begin{array}{l}\mathrm{EF} \\
(\%)\end{array}$ & $\leq 50$ & 0.465 & 0.340 & $0.307-0.600$ & $\begin{array}{c}46.0 \\
(52.4-81.3)\end{array}$ & $\begin{array}{c}49.0 \\
(51.3-79.2)\end{array}$ & 46.3 & 78.2 & 45.3 \\
\hline $\mathrm{E} / \mathrm{A}$ & $\leq 0.98$ & 0.455 & 0.396 & $0.417-0.742$ & $\begin{array}{c}45.2 \\
(53.3-81.2)\end{array}$ & $\begin{array}{c}44.3 \\
(41.3-69.5)\end{array}$ & 42.1 & 79.3 & 47.5 \\
\hline
\end{tabular}

PPV: positive predictive value; NPV: negative predictive value 


\section{Discussion}

SiMD is a well-known complication of sepsis in people (Nelson and Thompson, 2006; Dickinson et al., 2007). Reversible SiMD has been recognised in 20 to $60 \%$ of humans with sepsis (Martin et al., 2005; Subla et al., 2005; Vieillard-Baron, 2011). However, studies concerning SiMD in dogs are limited and the effect of SiMD on the prognosis in dogs is currently unknown.

There is a general consensus that EF is the most often used index for evaluating LV systolic function. However, its association with clinical outcome has given conflicting results, especially in patients with SS/SS (Ho and Solomon, 2006; Abdel-Hady et al., 2012; Naseri et al., 2019). Nelson and Thompson (2006) reported that $75 \%$ of dogs with an EF of less than $46 \%$ died or were euthanised within 15 days of hospital admission. However, in humans, it was found that reversible systolic dysfunction was associated with higher survival rates compared to those who did not survive (Jardin et al., 1999; Vieillard-Baron et al., 2008; Antonucci et al., 2014). In our study, three dogs with low EF $(<50 \%)$ survived. The difference in $\mathrm{EF}$ between $\mathrm{Sv}$ and non-Sv was significant $(\mathrm{P}<0.05$; Table 2). Nevertheless, the EF, an index of systolic dysfunction, had low sensitivity and specificity to differentiate $\mathrm{Sv}$ and non-Sv, with values of $46 \%(95 \%$ CI: $52.4-81.3$ ) and 49\% (95\% CI: 51.3-79.2), respectively, at an optimum cutoff point of $\leq 50$ (Table 3 ). Many hypotheses have been proposed to explain why survivors exhibited more marked myocardial depression (Hunter and Doddi, 2010; Vieillard-Baron, 2011; Weng et al., 2012). However, the exact pathophysiology of myocardial dysfunction is unclear. Myocardial hibernation in sepsis has been determined (Levy et al., 2005). Myocardial hibernation is an adaptive response to preserve cardiac myocytes by downregulation of oxygen consumption and energy requirements. Through this action, the activation of cell-death pathway may decrease and the future full recovery can start. The nonsignificantly increased cTnI in our study can also explain that physical myocardial injury is overlooked. Observed normal EF in most cases can be explained by persistent vasoplegia (decreased arterial tone). However, further serial studies are warranted to support this hypothesis.

LVS' is another parameter for LV systolic function. It has been proposed that LVS' could be a better prognostic index than EF (Yu et al., 2007). Weng et al. (2012) found that non-Sv exhibited significantly higher LVS' compared with Sv [11.0 cm/sec $(9.1$ to $12.5 \mathrm{~cm} / \mathrm{sec})$ versus $7.8 \mathrm{~cm} / \mathrm{sec}(5.5$ to $9.0 \mathrm{~cm} / \mathrm{sec})]$. In our study, LVS' also appeared to be a better prognostic index than EF. LVS' provided high sensitivity and specificity to differentiate Sv and non-Sv, with values of $83.3 \%$ (95\% CI: 41.6-98.4) and 83.3\% (95\% CI: 59.8-94.8), respectively, at an optimum cut-off point of $\geq 9.90$ (Table 3). Although the LVS' has advantages over EF, it is load dependent (Nguyen et al., 2007; Uemura et al., 2011). It has been reported that EF may correspond to different levels of intrinsic 
LV contractility. For instance, an EF of 55\% may correspond to impressed intrinsic LV contractility in the presence of vasoplegia (Robotham et al., 1991). So, the finding of supernormal LVS' in non-Sv in this study is not surprising (Table 2). Supernormal LVS' may reflect a hyperkinetic state associated with persistent and profound vasoplegia. Thus, high LVS' associated with persistent vasoplegia might be the cause of high mortality in dogs with SS/SS. However, further extensive studies need to be carried out in order to confirm our findings.

Studies in humans have shown that both systolic and diastolic dysfunction developed in patients with SS/SS (Poelaert et al., 1997; Munt et al., 1998; Bouhemad et al., 2008). Landesberg et al. (2012) reported that $9.1 \%$ of patients with $\mathrm{SS} / \mathrm{SS}$ had isolated systolic dysfunction and $14.1 \%$ had combined systolic and diastolic dysfunction. However, isolated diastolic dysfunction was more common $(38 \%)$. In other studies, alarmingly high prevalence rates (60-84\%) of left ventricular diastolic dysfunction with increased mortality have also been found in septic patients (Landesberg et al., 2012; Rolando et al., 2015; Souza Dantas and Costa, 2015). The prognostic importance of diastolic dysfunction in dogs with $\mathrm{SS} / \mathrm{SS}$ has not been adequately investigated. In this study, systolic (EF $\leq 50 \%)$ and diastolic dysfunction $\left(E^{\prime}<8 \mathrm{~cm} / \mathrm{s}\right)$ were present in three $(15 \%)$ and $14(70 \%)$ patients, respectively, and both types of dysfunctions were present in two $(10 \%)$ patients. Six dogs with diastolic dysfunction died. These results show that diastolic dysfunction in dogs with SS/SS is common (14 cases).

In humans, many studies have shown that E' is a load-independent measure of diastolic dysfunction (Landesberg et al., 2012) and has prognostic importance in cardiac diseases (Ho and Solomon, 2006; Yu et al., 2007). Sturgess et al. (2010) suggested that diastolic dysfunction was an independent predictor of mortality, better than cardiac biomarkers. In our study, E' was the best independent predictor of 28-day mortality in dogs with SS/SS (Table 2). E', an index of diastolic dysfunction, had the best sensitivity and specificity to differentiate $\mathrm{Sv}$ and non-Sv, with values of $100 \%$ (95\% CI: $55.2-100)$ and 100\% (95\% CI: $78.9-$ 100), respectively, at an optimum cut-off point of $\leq 6.50$ (Table 3). This result showed that LV diastolic dysfunction often developed in dogs with SS/SS, and E' was a good independent predictor of mortality. Diastolic dysfunction may impair LV dilatation and prevent stroke volume augmentation in response to fluid load, and the non-compliant LV may aggravate lung congestion. The developing non-cardiogenic pulmonary oedema may lead to pulmonary hypertension and right ventricle dysfunction.

A low mitral E/A ratio $(<1)$ may be an indicator of impaired ventricular relaxation and, consequently, diastolic dysfunction (Lavine, 2006). In this study, the mean $\mathrm{E} / \mathrm{A}$ ratio was lower $(\mathrm{P}<0.05)$ in non-Sv dogs than in control and $\mathrm{Sv}$ dogs (Table 2). However, the E/A had low sensitivity and specificity to differentiate $\mathrm{Sv}$ and non-Sv, with values of $45.2 \%$ (95\% CI: $53.3-81.2)$ and $44.3 \%(95 \%$ CI: 41.3-69.5), respectively, at an optimum cut-off point of $\leq 0.98$ (Table 3). So, 
we can state that E/A cannot be an important independent predictor of mortality in dogs with SS/SS.

In conclusion, echocardiographic systolic dysfunction determined by LVS' was associated with increased mortality in CPV-infected dogs with SS/SS. Diastolic dysfunction determined by E' was a good independent predictor of outcome.

\section{Acknowledgement}

The authors thank Enver Yazar for providing technical assistance in statistics.

\section{References}

Abdel-Hady, H. E., Matter, M. K. and El-Arman, M. M. (2012): Myocardial dysfunction in neonatal sepsis: A tissue Doppler imaging study. Pediatr. Crit. Care Med. 13, 318-323.

Antonucci, E., Fiaccadori, E., Donadello, K., Taccone, F. S., Franchi, F. and Scolletta, S. (2014): Myocardial depression in sepsis: from pathogenesis to clinical manifestations and treatment. J. Crit. Care 29, 500-511.

Bouhemad, B., Nicolas-Robin, A., Arbelot, C., Arthaud, M., Féger, F. and Rouby, J. J. (2008): Isolated and reversible impairment of ventricular relaxation in patients with septic shock. Crit. Care Med. 36, 766-774.

Bulmer, B. J. (2011): Cardiovascular dysfunction in sepsis and critical illness. Vet. Clin. Small Anim. 41, 717-726.

De Geer, L., Engvall, J. and Oscarsson, A. (2015): Strain echocardiography in septic shock - a comparison with systolic and diastolic function parameters, cardiac biomarkers and outcome. Crit. Care 19, 122.

Dickinson, A. E., Rozanski, E. A. and Rush, J. E. (2007): Reversible myocardial depression associated with sepsis in a dog. J. Vet. Intern. Med. 21, 1117-1120.

Ho, C. Y. and Solomon, S. D. (2006): A clinician's guide to tissue Doppler imaging. Circulation 113, 396-398.

Hunter, J. D. and Doddi, M. (2010): Sepsis and the heart. Br. J. Anaesth. 104, 3-11.

Jardin, F., Fourme, T., Page, B., Loubières, Y., Vieillard-Baron, A., Beauchet, A. and Bourdarias, J. P. (1999): Persistent preload defect in severe sepsis despite fluid loading: a longitudinal echocardiographic study in patients with septic shock. Chest 116, 1354-1359.

Kocaturk, M., Martinez, S., Eralp, O., Tvarijonaviciute, A., Ceron, J. and Yilmaz, Z. (2012): Tei index (myocardial performance index) and cardiac biomarkers in dogs with parvoviral enteritis. Res. Vet. Sci. 92, 24-29.

Krishnagopalan, S., Kumar, A., Parrillo, J. E. and Kumar, A. (2002): Myocardial dysfunction in the patient with sepsis. Curr. Opin. Crit. Care 8, 376-388.

Landesberg, G., Gilon, D., Meroz, Y., Georgieva, M., Levin, P. D., Goodman, S., Avidan, A., Beeri, R., Weissman, C., Jaffe, A. S. and Sprung, C. L. (2012): Diastolic dysfunction and mortality in severe sepsis and septic shock. Eur. Heart J. 33, 895-903.

Lavine, S. J. (2006): Effect of changes in contractility on the index of myocardial performance in the dysfunctional left ventricle. Cardiovasc. Ultrasound 4, 45.

Levy, R. J., Piel, D. A., Acton, P. D., Zhou, R., Ferrari, V. A., Karp, J. S. and Deutschman, C. S. (2005): Evidence of myocardial hibernation in the septic heart. Crit. Care Med. 33, 27522756. 
Mahjoub, Y., Benoit-Fallet, H., Airapetian, N., Lorne, E., Levrard, M., Seydi, A. A., Amennouche, N., Slama, M. and Dupont, H. (2012): Improvement of left ventricular relaxation as assessed by tissue Doppler imaging in fluid-responsive critically ill septic patients. Intensive Care Med. 38, 1461-1470.

Martin, R. S., Kincaid, E. H., Russell, H. M., Meredith, J. W. and Chang, M. C. (2005): Selective management of cardiovascular dysfunction in posttraumatic SIRS and sepsis. Shock 23, 202-208.

McMichael, M. (2014): Handbook of Emergency Protocols: Dog and Cat. 2nd edition. Wiley, Hoboken, NJ, USA.

Munt, B., Jue, J., Gin, K., Fennick, J. and Tweddale, M. (1998): Diastolic filling in human severe sepsis: an echocardiographic study. Crit. Care Med. 26, 1829-1833.

Nagueh, S. F., Appleton, C. P., Gillebert, T. C., Marino, P. N., Oh, J. K., Smiseth, O. A., Waggoner, A. D., Flachskampf, F. A., Pellikka, P. A. and Evangelista, A. (2009): Recommendations for the evaluation of left ventricular diastolic function by echocardiography. Eur. J. Echocardiogr. 10, 107-133.

Naseri, A., Sen, I., Turgut, K., Guzelbektes, H. and Constable, P. D. (2019): Echocardiographic assessment of left ventricular systolic function in neonatal calves with naturally occurring sepsis or septic shock due to diarrhea. Res. Vet. Sci. 126,103-112.

Nelson, O. L. and Thompson, P. A. (2006): Cardiovascular dysfunction in dogs associated with critical illnesses. J. Am. Anim. Hosp. Assoc. 42, 344-349.

Nguyen, H. B., Corbett, S. W., Steele, R., Banta, J., Clark, R. T., Hayes, S. R., Edwards, J., Cho, T. W. and Wittlake, W. A. (2007): Implementation of a bundle of quality indicators for the early management of severe sepsis and septic shock is associated with decreased mortality. Crit. Care Med. 35, 1105-1112.

Otto, C. M. (2007): Clinical trials in spontaneous disease in dogs: a new paradigm for investigations of sepsis. JVECC 17, 359-367.

Parrillo, J. E., Parker, M. M., Natanson, C., Suffredini, A. F., Danner, R. L., Cunnion, R. E. and Ognibene, F. P. (1990): Septic shock in humans. Advances in the understanding of pathogenesis, cardiovascular dysfunction, and therapy. Ann. Intern. Med. 113, 227-242.

Poelaert, J., Declerck, C., Vogelaers, D., Colardyn, F. and Visser, C. A. (1997): Left ventricular systolic and diastolic function in septic shock. Intensive Care Med. 23, 553-560.

Robotham, J. L., Takata, M., Berman, M. and Harasawa, Y. (1991): Ejection fraction revisited. Anesthesiology 74, 172-183.

Rolando, G., Espinoza, E. D. V., Avid, E., Welsh, S., Pozo, J. D., Vazquez, A. R., Arzani, Y., Masevicius, F. D. and Dubin, A. (2015): Prognostic value of ventricular diastolic dysfunction in patients with severe sepsis and septic shock. Rev. Bras. Ter. Intensiva 27, 333-339.

Silverstein, D. C. and Hoper, K. (2015): Small Animal Critical Care Medicine. 2nd edition. Elsevier Saunders, USA.

Souza Dantas, V. C. and Costa, V. A. (2015): A look at the diastolic function in severe sepsis and septic shock. Rev. Bras. Ter. Intensiva 27, 307-308.

Sturgess, D. J., Marwick, T. H., Joyce, C., Jenkins, C., Jones, M., Masci, P., Stewart, D. and Venkatesh, B. (2010): Prediction of hospital outcome in septic shock: a prospective comparison of tissue Doppler and cardiac biomarkers. Crit. Care 14, 44.

Subla, M. R., Khan, S. A., Behl, D. and Peters, S. G. (2005): Sepsis and myocardial depression in a young woman. Mayo Clin. Proc. 80, 810-814.

Turgut, K. (2017): Small Animal Clinic Cardiology. 1st edition. Nobel Tip Publishing, Istanbul, Turkey.

Uemura, K., Kawada, T., Sunagawa, K. and Sugimachi, M. (2011): Peak systolic mitral annulus velocity reflects the status of ventricular-arterial coupling - theoretical and experimental analyses. J. Am. Soc. Echocardiogr. 24, 582-591.

Vieillard-Baron, A. (2011): Septic cardiomyopathy. Ann. Intensive Care 1, 6. 
Vieillard-Baron, A., Caille, V., Charron, C., Belliard, G., Page, B. and Jardin, F. (2008): Actual incidence of global left ventricular hypokinesia in adult septic shock. Crit. Care Med. 36, 1701-1706.

Weng, L., Liu, Y. T., Du, B., Zhou, J. F., Guo, X. X., Peng, J. M., Hu, X. Y., Zhang, S. Y., Fang, Q. and Zhu, W. L. (2012): The prognostic value of left ventricular systolic function measured by tissue Doppler imaging in septic shock. Critical Care 16, R71.

Yu, C., Sanderson, J., Marwick, T. H. and Oh, J. (2007): Tissue Doppler imaging: a new prognosticator for cardiovascular diseases. J. Am. Coll. Cardiol. 49, 1903-1914. 